\title{
Reseña de Alonso Jerónimo de Salas Barbadillo, El caballero puntual, edición, estudio y notas de José Enrique López Martínez, Madrid, Real Academia Española/Centro para la Edición de los Clásicos Españoles, 2016, 446 pp. ISBN: 978-84-617-6806-6
}

\section{Manuel Piqueras Flores}

Universidad Autónoma de Madrid ESPAÑA manuel.piquerasflores@gmail.com

[Hipogrifo, (issn: 2328-1308), 7.1, 2019, pp. 735-738]

Recibido: 18-12-2018 / Aceptado: 14-01-2019

DOI: http://dx.doi.org/10.13035/H.2019.07.01.55

Si la Biblioteca Clásica de la Real Academia Española recoge las obras fundamentales del canon literario hispánico hasta el siglo XIX, en los Anejos de esta colección, editados también por la RAE en colaboración con el Centro para la Edición de los Clásicos Españoles, según su propia definición, «aparecen otros textos relevantes pero de menor categoría»' Tienen cabida, por tanto, obras de autores principales que no forman parte estricta de su canon -como el caso de El peregrino en su patria, de Lope de Vega-, así como obras de autores secundarios que, sin embargo, merecen una cierta atención por parte de los estudiosos, como la Poesía desconocida del Conde de Salinas o el Quijote de Avellaneda. En este segundo grupo cabría encuadrar El caballero puntual de Alonso Jerónimo de Salas Barbadillo, autor madrileño que desarrolló su carrera literaria a lo largo del primer tercio del siglo XVII, y más concretamente entre 1609 y 1635.

Salas Barbadillo compartió época con Cervantes, Lope de Vega, Góngora, Quevedo o Tirso de Molina, nombres indiscutibles dentro de la historia de la literatura española. En este sentido, es lógico que haya quedado como un escritor fuera del canon, aunque no puede decirse, ni mucho menos, que fuera un autor marginal. Al revés, quizá después de esos cinco gigantes de las letras, Salas sea el autor más interesante del periodo. Por ello, parece muy pertinente su inclusión en estos

1. http://www.rae.es/obras-academicas/bcrae/anejos, [14/08/2018]. 
Anejos, más aún con El caballero puntual, una de sus mejores novelas. La obra consta de dos partes: la primera fue publicada en 1614, en casa de Miguel Serrano, y tuvo una segunda edición en 1616, impresa por Juan de la Cuesta; la segunda parte, impresa por Francisco Abarca de Angulo, vio la luz en 1619, acompañada de la comedia Los prodigios del amor. Es, en este sentido, la única obra que Salas Barbadillo decidió continuar, lo que bien pudiera ser una muestra del aprecio que le tuvo. El personaje, en tanto que es un pícaro que se hace pasar por caballero en la corte, guarda similitudes con otros tipos semejantes de la literatura áurea, como el Caballero del Milagro que da título a una comedia picaresca de Lope de Vega, o con el Buscón de Quevedo, tal como muestra muy atinadamente López Martínez. Pero, además, la obra de Salas constituye uno de los más tempranos homenajes al don Quijote cervantino, ya que don Juan de Toledo, protagonista de la novela, no solo finge ser caballero, sino que acaba por creer que verdaderamente lo es. De hecho, entre las numerosas burlas que los ciudadanos de Madrid hacen a don Juan, destaca un epistolario ficticio entre los dos héroes, el uno denominado como caballero de la corte y el otro como caballero de las aldeas (pp. 71-79).

Más allá de los motivos estrictamente literarios, la recuperación de El caballero puntual resulta pertinente en tanto que no contábamos hasta la fecha con una edición moderna de la obra. Emilio Cotarelo la editó en 1909, en uno de los volúmenes de sus Obras de Alonso Jerónimo de Salas Barbadillo, pero, además de la antigüedad del trabajo, se trata de un texto que presenta muchos problemas, y que carece de anotación y de un estudio pertinente sobre la obra. López Martínez, en cambio, nos presenta un texto muy cuidado, editado conforme a criterios filológicos solventes, que toma como base para ambas partes sendas ediciones príncipe. Para la primera parte, el editor desecha como texto base la segunda edición, de 1616, que denomina testimonio $B$, en tanto que no hay pruebas de que las escasas variantes se hayan debido a la pluma de Salas (p. 179*2², pero sí lo utiliza para enmendar errores claros. El aparato crítico del texto recoge las variantes textuales (obviando las meramente gráficas o lingüísticas) de la edición de 1616 y también de la de Cotarelo.

Se opta por modernizar y unificar las grafías que no tienen valor fonológico, y desarrolla no so solamente las abreviaturas sino también las contracciones de la preposición de con pronombres y demostrativos, propias de la escritura áurea. En cuanto al uso de mayúsculas, López Martínez opta por mantener el título de la novela en minúscula -El caballero puntual-, es decir, como sintagma nominal común, mientras que utiliza la mayúscula en el apelativo del protagonista -«Caballero Puntual»-, como nombre propio. La decisión resulta lingüísticamente comprensible, pero en los preliminares de la segunda parte no se respeta, pues se edita Segunda parte del Caballero Puntual (p. 145, p. 146, p. 150, p. 151) o Caballero Puntual. Segunda parte (p. 147, p. 149) sin explicación aparente. Se trata, en cualquier caso, de un desliz sin importancia.

Esta edición no incluye Los prodigios del amor, comedia en verso publicada junto con la Segunda parte del Caballero Puntual, que sí contenía la edición de

2. La edición cuenta con dos numeraciones en arábigo, la de la introducción y la que comienza con el texto; la primera de ellas se acompaña de un asterisco para diferenciarla de la segunda. 
Cotarelo. Con cierta razón, parece que la decisión es consecuencia de considerar que la comedia es una obra exenta, sin relación literaria reseñable con la novela; no obstante, quizá hubiera sido mejor respetar el formato del libro tal y como se editó en 1619, pues en alguna medida El caballero puntual es, además de otras muchas cosas, un contenedor de otras formas literarias más breves, que se interpolan desde el final de la primera parte $y$, sobre todo, a lo largo de toda la segunda; $y$, en este sentido, bien puede entenderse Los prodigios de amor como una variante exenta de estas interpolaciones.

El texto, como hemos dicho, viene acompañado de un extenso estudio introductorio (más de ciento ochenta páginas) divido en tres partes, más una cuarta que se ocupa de los criterios de edición. En primer lugar, tenemos un acercamiento la vida y obra de Salas Barbadillo, que expone los datos más relevantes de la carrera literaria del autor madrileño y consigue que el lector se familiarice con su figura (pp. 9*-33*). No hay nada reseñable que falte en estas páginas, que actualizan lo aportado por Uhagón y Cotarelo en las primeras ediciones relativamente modernas de Salas; y que, con toda probabilidad, son una síntesis de la biografía que el propio López Martínez ha preparado sobre el escritor, que, como él mismo anuncia, se publicará de manera inminente (p. 9*).

El segundo epígrafe de esta introducción, el más extenso (pp. 33*-137*), se titula «Estructura y fuentes de El caballero puntual» y, ciertamente, a través de la estructura y de las fuentes del texto se despliega un detallado análisis de la novela, prácticamente capítulo por capítulo. Aquí López Martínez muestra no solamente su conocimiento sobre la obra en cuestión y sobre Salas Barbadillo, sino también sobre la literatura de la época. Con todo, el apartado más interesante en nuestra opinión es el titulado «De la picaresca a la literatura de burlas» (pp. 137*-178*), que incide en el espíritu genérico de la novela y en su evolución a lo largo de las dos partes. El análisis se ilumina en numerosas ocasiones con pasajes de otras obras de Salas con características comunes a El caballero puntual, y muestra la importancia de la novela de burlas en la creación del autor.

En cuanto a la anotación, como es sabido, los Anejos de la Biblioteca Clásica de la RAE, al igual que la propia Biblioteca Clásica, incorpora un doble sistema: al pie se realizan apuntes sucintos, necesarios para la comprensión del texto, que en ciertos casos se amplían con notas complementarias al final. El editor lo aprovecha notablemente, sabiendo elegir con pertinencia lo que corresponde a cada nivel; de esta manera, la anotación complementaria, que ocupa por sí sola casi ciento cincuenta páginas, provee al lector especializado de un conocimiento profundo no solo de la novela, sino también del resto de la obra de Salas y de su contexto literario.

La bibliografía presentada se adecúa al rigor que presenta el resto del trabajo, y en ella encontramos todo aquello que resulta relevante sobre Salas Barbadillo, hasta el punto de que se incluye la única edición moderna de Las fiestas de la boda de la incasable malcasada, una desconocida tesis de licenciatura inédita realizada por María Bascuas, ejemplo del trabajo que hay tras este volumen. Solo se echa en 
falta un artículo publicado por Armine Manukyan ${ }^{3}$ en el año 2012 y la edición de Don Diego de Noche efectuada por Enrique García-Santo Tomás (Madrid, Cátedra, 2013).

Más allá de puntillosos apuntes que no pretenden en absoluto desmerecer el objeto de análisis, el resultado de conjunto nos parece magnífico. El libro recoge todo aquello que se le puede pedir a una edición de estas características: un texto editado según criterios filológicos fiables, un estudio de la obra -hasta ahora prácticamente desconocida- que la analiza en profundidad y destaca sus aspectos más relevantes, y una anotación no solo precisa, sino erudita, que completa la comprensión del texto. Estamos ante la mejor edición de una obra de Salas Barbadillo realizada hasta la fecha; esperemos que avive el interés por el autor, y que sirva como preanuncio de otros muchos de sus textos que aún están esperando ser editados filológicamente.

3. Manukyan, Armine, «Salas Barbadillo entre sus contemporáneos: sus qustos literarios e influencias», en «Scripta manent». Actas del I Congreso Internacional Jóvenes Investigadores Siglo de Oro (JISO 2017), Carlos Mata Induráin y Adrián J. Sáez (eds.), Pamplona, Servicio de Publicaciones de la Universidad de Navarra, 2012, pp. 279-295. 